\title{
Editorial: Socio-Ecology of Microbes in a Changing Ocean
}

\author{
Matthias Wietz ${ }^{1 *}$, Stanley C. Lau ${ }^{2}$ and Tilmann Harder ${ }^{1,3}$ \\ ${ }^{1}$ Alfred Wegener Institute Helmholtz Centre for Polar and Marine Research, Bremerhaven, Germany, ${ }^{2}$ Division of Life \\ Science, The Hong Kong University of Science and Technology, Clear Water Bay, Hong Kong, ${ }^{3}$ Faculty of Biology and \\ Chemistry, University of Bremen, Bremen, Germany
}

Keywords: symbioses, microbe-host interactions, phytoplankton, marine bacteria, microbial networks, holobiont ecology, climate change

\section{Editorial on the Research Topic}

\section{Socio-Ecology of Microbes in a Changing Ocean}

\section{OPEN ACCESS}

Edited by:

Hongyue Dang,

Xiamen University, China

Reviewed by:

Gian Marco Luna, Italian National Research Council (CNR), Italy

Michael Joseph Behrenfeld

Oregon State University,

United States

*Correspondence:

Matthias Wietz

matthias.wietz@awi.de

Specialty section: This article was submitted to

Aquatic Microbiology,

a section of the journal

Frontiers in Marine Science

Received: 22 December 2018 Accepted: 26 March 2019

Published: 16 April 2019

Citation:

Wietz M, Lau SC and Harder T (2019) Editorial: Socio-Ecology of Microbes in a Changing Ocean.

Front. Mar. Sci. 6:190.

doi: 10.3389/fmars.2019.00190
Marine microbes live in complex socio-ecological networks with diverse microbial and macrobial neighbors. These networks operate on different scales, spanning the single-cell level to microhabitats and (meta)communities to entire phytoplankton blooms (Faust and Raes, 2012; Teeling et al., 2012; Cordero and Datta, 2016). Boosted by recent advances in next-generation sequencing and high-resolution chemical analyses, the scientific community begins to unveil the complexity of microbial relationships and how these interactions influence biological dynamics and holobiont functioning (Pita et al., 2018; Van De Water et al., 2018). Ultimately, the elucidation of microbial network processes helps with the interpretation of large-scale ecological and biogeochemical events (Strom, 2008; Fuhrman et al., 2015).

The Frontiers Research Topic Socio-Ecology of Microbes in a Changing Ocean invited contributions on microbial signaling and communication, the effect of microbial interactions on microhabitat structuring, the function of secondary metabolites in bacterial antagonism and microbe-host interactions, the conversion and cross-feeding of nutrients, microbial physiology and gene regulation in response to co-occurring organisms, as well as metabolic exchange in diverse communities. Special emphasis was placed on socio-ecological dynamics under a changing climate, addressing the biological effects of ocean acidification and warming and the increasing spread of invasive species.

The Research Topic encompasses 16 papers on diverse aspects of microbial cooperation and competition, such as bacterial interactions with phytoplankton, macroalgae and invertebrates, chemical microdiversity, interkingdom signaling, viral infections of macroalgae, as well as the distribution of archaea and fungi in relation to environmental parameters. In addition, one Review and one Perspective article offer exciting views on coral disease and phytoplankton multicellularity.

\section{BACTERIA-ALGAE INTERACTIONS}

Interactions between bacteria and algae are a major focus of the Research Topic, reflecting the pivotal role of micro- and macroalgae in marine carbon fluxes (Falkowski and Woodhead, 1992; Field et al., 1998) and associated microbial dynamics (Amin et al., 2012; Martin et al., 2014; Seymour et al., 2017). Contributed papers highlight the importance of bacteria for algae and vice versa, describing the composition and function of associated microbiota, interdependencies by metabolite exchange, and how these interactions can vary under changing environmental conditions.

In their paper "Bacterial Communities of Diatoms Display Strong Conservation Across Strains and Time," Behringer et al. show that the diatoms Asterionellopsis glacialis and Nitzschia longissima harbor conserved microbiota that remain stable over 1 year of co-existence. These distinct and 
consistent temporal associations are linked to a range of bacterial processes that enhance diatom growth. The concept of specific associations between bacteria and microalgae is supported by Crenn et al. in their paper "Bacterial Epibiotic Communities of Ubiquitous and Abundant Marine Diatoms Are Distinct in Short- and Long-Term Associations." Here, screening of single Thalassiosira and Chaetoceros cells demonstrates that laboratory experiments select for specific diatom microbiota adapted to long-term associations, whereas environmental diatoms harbor different bacterial associates. A step toward deciphering the molecular mechanisms behind such interactions is made by Torres-Monroy and Ullrich in their paper "Identification of Bacterial Genes Expressed During DiatomBacteria Interactions Using an in vivo Expression Technology Approach." Here, bacterial gene expression is studied in response to the diatom Thalassiosira weissflogii, revealing specific expression of bacterial promoters during interactions with T. weissflogii. These observations correspond to specific regulation of bacterial attachment, nitrogen metabolism and heavy metal resistance. Interactions between algae and bacteria also include the exchange of ecologically relevant metabolites, as demonstrated by Wienhausen et al. in "The Exometabolome of Two Model Strains of the Roseobacter Group: A Marketplace of Microbial Metabolites." Here, ultrahigh-resolution mass spectrometry reveals diverse exometabolites secreted by the bacteria Phaeobacter inhibens and Dinoroseobacter shibae, including plant auxins and precursors of different B vitamins that may benefit co-occurring auxotrophs. A related scenario is presented in "The B-Vitamin Mutualism Between the Dinoflagellate Lingulodinium polyedrum and the Bacterium Dinoroseobacter shibae" by Cruz-López et al. who describe that $D$. shibae is dependent on vitamin $\mathrm{B}_{7}$ produced by L. polyedrum while in turn providing vitamins $\mathrm{B}_{1}$ and $\mathrm{B}_{12}$ to the eukaryotic partner. Yarimizu et al. describe another type of bacterial interaction with this dinoflagellate species in their paper "Iron and Harmful Algae Blooms: Potential Algal-Bacterial Mutualism Between Lingulodinium polyedrum and Marinobacter algicola." Here, M. algicola is shown as essential for dinoflagellate growth by supplying bioavailable iron via the siderophore vibrioferrin. As L. polyedrum can be a major cause of harmful algal blooms, bacteria-algae interactions can hence also have detrimental ecological and economic consequences. This alternative perspective is also addressed by Bramucci et al. in "The Bacterial Symbiont Phaeobacter inhibens Shapes the Life History of Its Algal Host Emiliania huxleyi." During long-term co-cultivation, $P$. inhibens selectively kills calcifying and flagellated types of the coccolithophore Emiliania huxleyi, whereas non-calcifying E. huxleyi remain unaffected. This differential pathogenesis may alter the composition of E. huxleyi blooms, with probable consequences for marine primary production.

The section on bacteria-algae interactions also includes two papers on macroalgae and associated microbes. Macroalgae are important primary producers in coastal environments and have central functions as habitat formers and nutrient source, but are threatened by environmental stressors (Steneck and Erlandson, 2002; Krumhansl et al., 2016). In their paper "Novel ssDNA
Viruses Detected in the Virome of Bleached, Habitat-Forming Kelp Ecklonia radiata," Beattie et al. shotgun-sequenced viral particles isolated from healthy and diseased phenotypes of the kelp Ecklonia radiata. This approach identified novel ssDNA viruses restricted to bleached kelp, indicating that stress-induced viral infections may affect coastal primary production. The view on macroalgae-associated microbes is complemented by the paper "Exploring the Cultivable Ectocarpus Microbiome," where KleinJan et al. isolated over 300 bacterial strains associated with the brown macroalga Ectocarpus subulatus. This first step toward a model system for functional studies of algae-bacteria interactions during abiotic stress is highly relevant for futureocean scenarios in the wake of climate change.

The collection of papers related to bacteria and algae concludes with a Perspective article raising thought-provoking concepts about "Multicellular Features of Phytoplankton." Here, Abada and Segev propose that microalgal populations often display the characteristics of a multicellular-like community; representing an evolutionary intermediate between single cells and aggregates that communicate and cooperate. By combining evidence on coccolithophores and diatoms, two key phytoplankton groups, the authors discuss exciting aspects such as coordinated behavior and programmed cell death in a multicellular context.

\section{BACTERIA-CNIDARIA INTERACTIONS}

Studies on functional interactions between cnidarian hosts and microbes are receiving continued interest, particularly owing to ecological threats connected to climate change, for instance coral bleaching (Pandolfi et al., 2003; Bourne et al., 2016). This Research Topic includes four related papers, including the Review "Responses of Coral-Associated Bacterial Communities to Local and Global Stressors." Here, McDevitt-Irvin et al. summarize 45 recent studies to show that coral health can be strongly influenced by microbiome composition, illustrating that stress-related shifts in bacterial diversity may have important ecological consequences. A second coral-related contribution, "Quorum Sensing Interference and Structural Variation of Quorum Sensing Mimics in Australian Soft Coral" by Freckelton et al. describes how coral-derived metabolites mimic bacterial signaling molecules and hence influence cellcell communication. The finding of chemical crosstalk between soft corals and their associated bacteria is important considering the ecological network within the coral holobiont. Another type of cnidarian, the sea anemone Nematostella, is investigated in the paper "Predicted Bacterial Interactions Affect in vivo Microbial Colonization Dynamics in Nematostella" by Domin et al. Through bacterial cultivation and co-occurrence networks, bacteria-bacteria interactions are shown to change according to the host's developmental stage. Predicted competitive bacteria influence community structure for a short period of time but are soon replaced, indicating a high degree of resilience within the bacterial community. In their paper "Stimulated Respiration and Net Photosynthesis in Cassiopeia sp. during Glucose Enrichment Suggests in hospite $\mathrm{CO}_{2}$ Limitation of Algal 
Endosymbionts," Rädecker et al. show that glucose enrichment stimulates respiration and photosynthesis in the holobiont of upside-down jellyfish, likely resulting from bacterial activity that subsequently stimulates primary production by algal symbionts through increased $\mathrm{CO}_{2}$ availability.

\section{EFFECTS OF ENVIRONMENTAL PARAMETERS ON MICROBIAL DISTRIBUTION}

The third section of the Research Topic includes two papers on the distribution of microbes in relation to environmental parameters (Hanson et al., 2012; Sunagawa et al., 2015). Whereas biogeographical patterns are comparatively wellstudied for bacteria, Müller et al. focus on archaea by resolving "Spatiotemporal Dynamics of Ammonia-Oxidizing Thaumarchaeota in Distinct Arctic Water Masses." The authors describe distributional patterns of Thaumarchaeota genotypes in specific water masses in the Arctic-Atlantic boundary, a region under special threat from climate change. Considering the thaumarchaeotal contribution to ammonia oxidation, these findings have implications for nitrogen cycling. Finally, the paper "Spatiotemporal Distribution and Assemblages of Planktonic Fungi in the Coastal Waters of the Bohai Sea" by Wang et al. illustrates regional and temporal changes in the abundance

\section{REFERENCES}

Amin, S. A., Parker, M. S., and Armbrust, E. V. (2012). Interactions between diatoms and bacteria. Microbiol. Mol. Biol. Rev. 76, 667-684. doi: 10.1128/MMBR.00007-12

Bourne, D. G., Morrow, K. M., and Webster, N. S. (2016). Insights into the coral microbiome: underpinning the health and resilience of reef ecosystems. Annu. Rev. Microbiol. 70, 317-340. doi: 10.1146/annurev-micro-102215-095440

Cordero, O. X., and Datta, M. S. (2016). Microbial interactions and community assembly at microscales. Curr. Opin. Microbiol. 31, 227-234. doi: 10.1016/j.mib.2016.03.015

Falkowski, P. G., and Woodhead, A. D. (1992). Primary Productivity and Biogeochemical Cycles in the Sea. New York, NY: Plenum Press.

Faust, K., and Raes, J. (2012). Microbial interactions: from networks to models. Nat. Rev. Microbiol. 10, 538-550. doi: 10.1038/nrmicro2832

Field, C. B., Behrenfeld, M. J., Randerson, J. T., and Falkowski, P. (1998). Primary production of the biosphere: integrating terrestrial and oceanic components. Science 281, 237-240. doi: 10.1126/science.281.5374.237

Fuhrman, J. A., Cram, J. A., and Needham, D. M. (2015). Marine microbial community dynamics and their ecological interpretation. Nat. Rev. Microbiol. 13, 133-146. doi: 10.1038/nrmicro3417

Hanson, C. A., Fuhrman, J. A., Horner-Devine, M. C., and Martiny, J. B. H. (2012). Beyond biogeographic patterns: processes shaping the microbial landscape. Nat. Rev. Microbiol. 10, 497-507. doi: 10.1038/nrmicro2795

Krumhansl, K. A., Okamoto, D. K., Rassweiler, A., Novak, M., Bolton, J. J., Cavanaugh, K. C., et al. (2016). Global patterns of kelp forest change over the past half-century. Proc. Natl. Acad. Sci. U.S.A. 113, 13785-13790. doi: $10.1073 /$ pnas. 1606102113

Martin, M., Portetelle, D., Michel, G., and Vandenbol, M. (2014). Microorganisms living on macroalgae: diversity, interactions, and biotechnological applications. Appl. Microbiol. Biotechnol. 98, 2917-2935. doi: 10.1007/s00253-014-5557-2

Pandolfi, J. M., Bradbury, R. H., Sala, E., Hughes, T. P., Bjorndal, K. A., Cooke, R. G., et al. (2003). Global trajectories of the long-term decline of coral reef ecosystems. Science 301, 955-958. doi: 10.1126/science.1085706 and diversity of fungi, a so-far largely unexplored group of marine microbes. Differential distribution of Ascomycota and Basidiomycota between coastal habitats was related to riverine inputs and phytoplankton detritus, providing insights into the ecology of fungi in marine systems.

\section{CONCLUSIONS AND PERSPECTIVES}

As evidenced by the contributions to this Research Topic, the socio-ecology of microbes is a growing field of research that substantially benefits from cross-disciplinary approaches. The diverse Topic contributions showcase that the field is clearly moving from merely descriptive analyses of "whois-associated-with-whom" to functional studies of diversity and phenotypic traits within metaorganisms, which harbor a network of associates from all domains of life. Holistic perspectives and systemic analyses, which acknowledge the complexity and linkages within biological systems, are fundamental for the comprehensive understanding of ecological and biogeochemical processes, particularly in the wake of climate change.

\section{AUTHOR CONTRIBUTIONS}

This editorial was co-authored by the Topic Editors MW, SL, and $\mathrm{TH}$.

Pita, L., Rix, L., Slaby, B. M., Franke, A., and Hentschel, U. (2018). The sponge holobiont in a changing ocean: from microbes to ecosystems. Microbiome 6:46. doi: 10.1186/s40168-018-0428-1

Seymour, J. R., Amin, S. A., Raina, J. B., and Stocker, R. (2017). Zooming in on the phycosphere: the ecological interface for phytoplankton-bacteria relationships. Nat. Microbiol. 2, 17065. doi: 10.1038/nmicrobiol.2017.65

Steneck, R., and Erlandson, J. M. (2002). Kelp forest ecosystems: biodiversity, stability, resilience and future. Environ. Conserv. 29, 436-459. doi: $10.1017 /$ S0376892902000322

Strom, S. L. (2008). Microbial ecology of ocean biogeochemistry: a community perspective. Science 320, 1043-1045. doi: 10.1126/science.1153527

Sunagawa, S., Coelho, L. P., Chaffron, S., Kultima, J. R., Labadie, K., Salazar, G., et al. (2015). Structure and function of the global ocean microbiome. Science 348:1261359. doi: 10.1126/science.12 61359

Teeling, H., Fuchs, B. M., Becher, D., Klockow, C., Gardebrecht, A., Bennke, C. M., et al. (2012). Substrate-controlled succession of marine bacterioplankton populations induced by a phytoplankton bloom. Science 336, 608-611. doi: $10.1126 /$ science. 1218344

Van De Water, J. A. J. M., Allemand, D., and Ferrier-Pagès, C. (2018). Host-microbe interactions in octocoral holobionts - recent advances and perspectives. Microbiome 6:64. doi: 10.1186/s40168-0180431-6

Conflict of Interest Statement: The authors declare that the research was conducted in the absence of any commercial or financial relationships that could be construed as a potential conflict of interest.

Copyright (c) 2019 Wietz, Lau and Harder. This is an open-access article distributed under the terms of the Creative Commons Attribution License (CC BY). The use, distribution or reproduction in other forums is permitted, provided the original author(s) and the copyright owner(s) are credited and that the original publication in this journal is cited, in accordance with accepted academic practice. No use, distribution or reproduction is permitted which does not comply with these terms. 